\title{
Implante de condrócitos homólogos em defeitos osteocondrais de cães: padronização da técnica e avaliação histopatológica
}

\author{
[Homologous articular chondrocytes implantation in osteochondral defects of dogs: technique and \\ histopathological evaluation standardization] \\ L.S. Iamaguti ${ }^{1}$, C.V.S. Brandão ${ }^{1}$, L.S.L.S. Mota ${ }^{2}$, J.J.T. Ranzani ${ }^{1}$, L.M. Ribeiro ${ }^{2}$, \\ V.J.V. Rossetto ${ }^{1}$, C.R. Padovani ${ }^{2}$, S.L. Felisbino ${ }^{2}$ \\ ${ }^{1}$ Faculdade de Medicina Veterinária e Zootecnia - Unesp - Botucatu, SP \\ ${ }^{2}$ Instituto de Biociências de Botucatu - Unesp - Botucatu, SP \\ RESUMO
}

\begin{abstract}
Padronizou-se a metodologia para cultura de condrócitos em cães e avaliou-se seu implante em lesões osteocondrais, utilizando-se a membrana biossintética de celulose (MBC) como revestimento. Dez cães, adultos e clinicamente sadios, foram submetidos à artrotomia das articulações fêmoro-tíbio-patelares. Defeitos de $4 \mathrm{~mm}$ de diâmetro e profundidade foram induzidos no sulco troclear de ambos os membros. MBC foi aplicada na base e na superfície das lesões. Os defeitos do membro direito foram preenchidos com condrócitos homólogos cultivados formando o grupo-tratado (GT); os do membro esquerdo, sem implante celular, foram designados grupo-controle (GC). A evolução pós-operatória foi analisada com especial interesse nos processos de reparação da lesão, por meio de histomorfometria e imunohistoquímica para colágeno tipo II e sulfato de condroitina. A cultura de condrócitos homólogos apresentou alta densidade e taxa de viabilidade. Observou-se integridade do tecido neoformado com a cartilagem adjacente na avaliação histológica, em ambos os grupos. Na imuno-histoquímica, verificou-se predomínio de colágeno tipo II no GT. Morfometricamente, não houve diferença significativa entre o tecido fibroso e o fibrocartilaginoso entre os grupos. A cultura de condrócitos homólogos de cães foi exequível. O tecido neoformado apresentou qualidade discretamente superior associado ao implante homólogo de condrócitos, contudo não promoveu reparação por cartilagem hialina.
\end{abstract}

Palavras-chave: cão, cartilagem articular, cultura celular, imuno-histoquímica, morfometria

\begin{abstract}
The aim of the study is to standardize the methodology to achieve canine chondrocytes culture, and evaluate its implant on osteochondral defects made in the femoral trochlear sulcus of dogs, using the cellulose biosynthetic membrane (CBM) as coating. Ten healthy adult dogs without locomotor disorders were used. All animals were submitted to arthrotomy of stifle joints and defects of four millimeters in diameter $x$ four millimeters deep were done in the femoral trochlear sulcus of both limbs. CBM were applied in the lesion base and surface of all limbs. In the treated group (TG), defects of the right limb were filled with cultivated homologous chondrocytes, and in control group (CG), defects of the left limb were left without cellular implant. Postoperative follow up was done by histomorphometry and Collagen type II and anti-chondroitin sulfate immunohistochemistry. The homologous chondrocytes culture showed high density and viability rate. Upon immunohistochemistry the predominance of type II collagen in extracellular matrix of TG was verified. However, no significant statistical difference was observed between the groups upon histomorphometry analysis of fibrous and fibrocartilaginous tissues. Canine homologous chondrocytes culture was practicable. Neoformed tissue showed slightly higher quality in $T G$, but without promoting repair by the hyaline cartilage.
\end{abstract}

Keywords: dog, articular cartilage, cell culture, immunohistochemistry, morphometry

Recebido em 5 de agosto de 2011

Aceito em 25 de agosto de 2012

E-mail: iamaguti_lu@hotmail.com 


\section{INTRODUÇÃO}

Traumas ou instabilidade articular frequentemente induzem a lesões importantes na cartilagem articular. Um elemento estratégico para o sucesso na reparação desses defeitos consiste no uso de materiais biológicos com ou sem implante celular (Van der Kraan et al., 2002).

Membranas biossintéticas apresentam boa aceitação pelo organismo; protegem e auxiliam a reparação de áreas lesadas por permeabilidade seletiva, além de impedirem a contaminação por microrganismos (Aslan et al., 2004). A membrana biossintética à base de celulose (MBC) foi aplicada em trocleoplastias experimentais em cães e não interferiu na biomecânica e nem no ambiente intraarticular (Iamaguti et al., 2008a). Além disso, acelerou o processo de reparação inicial da região da trocleoplastia, apresentando boa integração do tecido neoformado com a cartilagem adjacente. Contudo, como elemento isolado, não foi efetiva para promover completa regeneração da cartilagem articular (Iamaguti et al., 2008b).

O implante autólogo de condrócitos cultivados foi descrito em humanos e cães, sendo relatada a reparação com presença de formação de cartilagem hialina na maioria dos casos (Brittberg et al., 1994). A principal desvantagem do uso de condrócitos autólogos e sua ampla aplicação prática são a baixa disponibilidade, tanto em localização quanto em quantidade para a obtenção das células cartilaginosas para o cultivo. Boopalan et al. (2006) realizaram implante articular alógeno em coelhos, descreveram boa taxa de sucesso e ausência de resposta imunogênica. Entretanto, na literatura consultada, não foram encontrados estudos de implante homólogo de condrócitos em ambiente articular em cães.

Frente aos aspectos citados, objetivou-se padronizar a cultura de condrócitos homólogos em cães e analisar a reparação do tecido cartilaginoso em defeitos experimentais profundos com a utilização da MBC, como revestimento, associada ao implante celular.

\section{MATERIAL E MÉTODOS}

A metodologia instituída foi aprovada pela Comissão de Ética da Faculdade de Medicina Veterinária e Zootecnia - UNESP - Botucatu, sob protocolo $n^{\circ}$ 62/2009. Foram doadores de cartilagem hialina dois cães, de um e cinco anos de idade, que vieram a óbito por motivos não infecciosos ou neoplásicos, e sem alterações macroscópicas nas articulações. A coleta foi realizada imediatamente após o óbito. Foram coletados fragmentos de cartilagem das articulações fêmoro-tíbio-patelares, coxofemorais, úmero-rádioulnares e escapuloumerais. Estes foram imersos no meio de cultura Ham F-12 (Nutrient Mixture, GIBCO, Invitrogen Brasil Ltda., São Paulo - SP) durante, no máximo, seis horas.

A cartilagem articular hialina coletada foi seccionada em fragmentos de cerca de $1 \mathrm{~mm}^{3}$ sob fluxo laminar. Estes foram imersos em solução $(0,375 \mathrm{mg} / \mathrm{mL})$ de colagenase (Colagenase Type 2 CLS 2, Worthington Biochemical Corporation, Lakewood - New Jersey) filtrada, transferidos para frascos de cultivos de $25 \mathrm{~cm}^{2}$ e incubados a $38^{\circ} \mathrm{C}$ por 16 horas em estufa com $\mathrm{CO}^{2}$ a $5 \%$ para digestão enzimática. A contagem do número de células em $1 \mathrm{~mL}$ de solução e porcentagem de viabilidade foram realizadas utilizando-se o corante azul de tripan, em câmara hemocitométrica (Neubauer).

A solução foi centrifugada durante 10 minutos a 1500 rpm, padrão de centrifugação utilizado. Descartado o sobrenadante, o pellet foi ressuspendido em $5 \mathrm{~mL}$ de meio Ham F-12 e centrifugado; esse procedimento foi repetido duas vezes. A seguir, após a ressuspensão do pellet, este foi acrescido de $10 \%$ de soro fetal bovino (Invitrogen Brasil Ltda. - SP) e $1 \%$ de penicilina/estreptomicina (Invitrogen Brasil Ltda. $\mathrm{SP})$.

O conteúdo foi transferido para os frascos de cultivos por 15 dias. Análises morfológicas das células foram realizadas rotineiramente utilizandose microscópio invertido Leica DM IL em contraste de fase. No ápice da multiplicação celular, estas foram isoladas utilizando-se solução de tripsina versene (ATV, Tripsina 0,2\% e Versene 0,02\%, Instituto Adolfo Lutz -SP) por três minutos, lavadas em meio de cultivo, e o material centrifugado. $\mathrm{O}$ pellet foi ressuspendido em solução de Ham F-12, soro fetal bovino e antibiótico. As células foram, então, cultivadas em tubo de centrífuga a $38^{\circ} \mathrm{C}$, posicionadas verticalmente, por mais 10 dias, sendo, a seguir, efetuada a contagem para o número total de células e viabilidade celular.

Para o implante, foram utilizados 10 cães sadios, sem raça definida, provenientes de Biotério Central, sendo três fêmeas e sete machos, com faixa etária entre um e seis anos, e peso médio de $12,5 \pm 4,5 \mathrm{~kg}$. Todos os animais foram submetidos ao procedimento de artrotomia de ambas as articulações fêmoro-tíbio-patelares (Iamaguti et al., 
2008 b), sendo realizado um defeito de $4 \mathrm{~mm}$ de diâmetro e profundidade em cada sulco troclear. No membro esquerdo (grupo-controle - GC), a MBC foi aplicada na base e na superfície das lesões; no membro direito (grupo-tratado - GT), além da $\mathrm{MBC}$, nos defeitos foram implantados condrócitos homólogos cultivados.

Aos 60 dias do pós-operatório, foi realizada artrotomia exploratória para obtenção de biópsia da região do defeito, visando ao exame histomorfométrico e imuno-histoquímico. Os fragmentos coletados foram fixados em formaldeído a $10 \%$ e descalcificados em solução de ácido acético a $10 \%$ e formaldeído a $10 \%$ em água destilada, a seguir incluídos em parafina. A microtomia consistiu de cortes seriados de cinco micrômetros de espessura. As lâminas foram coradas com hematoxilina-eosina, azul de toluidina e picrossírius, e examinadas por microscopia fotônica convencional.
$\mathrm{Na}$ análise histológica, a resposta biológica foi determinada em função do processo de reparação da cartilagem, alterações vasculares e infiltrado inflamatório. As secções foram examinadas de acordo com a escala de classificação histológica modificada, contendo 13 categorias com pontuação máxima de 39 pontos (O'Driscoll et al., 1986; Pineda et al., 1992; Wilke et al., 2007). As categorias estudadas foram: preenchimento do defeito na região central, características estruturais na lesão - regularidade da superfície, integridade estrutural do defeito, espessura da lesão, integração com cartilagem adjacente -, alterações degenerativas na cartilagem adjacente, presença de condrócitos perilesionais, morfologia celular na lesão, coloração azul de toluidina da matriz na lesão; coloração azul de toluidina da lesão em relação à cartilagem adjacente, coloração picrosírius na lesão em relação à cartilagem adjacente, predomínio de colágeno tipo II e predomínio de sulfato de condroitina. Os escores utilizados estão apresentados na Tab. 1 .

Tabela 1. Mediana e valores mínimo e máximo das variáveis, segundo os grupos, em cães submetidos à artrotomia da articulação fêmoro-tíbio-patelar

\begin{tabular}{lccc} 
& Controle & Tratado & Valor p \\
\hline Preenchimento do defeito & $8,0(6,0 ; 8,0)$ & $8,0(6,0 ; 8,0)$ & $\mathrm{P}>0,05$ \\
Regularidade da superfície da lesão & $2,0(1,0 ; 2,0)$ & $2,0(2,0 ; 2,0)$ & $\mathrm{P}>0,05$ \\
Integridade da superfície da lesão & $2,0(2,0 ; 2,0)$ & $2,0(2,0 ; 2,0)$ & $\mathrm{P}>0,05$ \\
Espessura da lesão & $2,0(1,0 ; 2,0)$ & $2,0(1,0 ; 2,0)$ & $\mathrm{P}>0,05$ \\
Integração com cartilagem adjacente & $2,0(2,0 ; 2,0)$ & $2,0(2,0 ; 2,0)$ & $\mathrm{P}>0,05$ \\
Ausência de alterações degenerativas & $3,0(2,0 ; 3,0)$ & $3,0(2,0 ; 3,0)$ & $\mathrm{P}>0,05$ \\
Condrócitos perilesionais & $3,0(2,0 ; 3,0)$ & $3,0(3,0 ; 3,0)$ & $\mathrm{P}>0,05$ \\
Morfologia celular na lesão & $0,0(0,0 ; 1,0)$ & $1,0(1,0 ; 1,0)$ & $\mathrm{P}<0,05$ \\
Coloração da matriz na lesão & $2,0(2,0 ; 2,0)$ & $2,0(2,0 ; 2,0)$ & $\mathrm{P}>0,05$ \\
Coloração azul de toluidina* & $1,0(0,0 ; 1,0)$ & $1,0(0,0 ; 1,0)$ & $\mathrm{P}>0,05$ \\
Coloração de picrossírius* & $3,0(1,0 ; 3,0)$ & $3,0(2,0 ; 3,0)$ & $\mathrm{P}>0,05$ \\
Predomìnio de colágeno tipo II* & $0,0(0,0 ; 0,0)$ & $0,5(0,0 ; 1,0)$ & $\mathrm{P}<0,05$ \\
Predomínio de sulfato de condroitim* & $1,0(0,0 ; 1,0)$ & $1,0(0,0 ; 1,0)$ & $\mathrm{P}>0,05$ \\
Total de pontos & $27,0(23,0 ; 30,0)$ & $29,5(25,0 ; 31,0)$ & $\mathrm{P}<0,05$ \\
\hline
\end{tabular}

Legenda: Preenchimento do defeito: 8 (80,1 - 100\%), 6 (60,1 - 80\%);

regularidade da superfície da lesão: 2 (lisa e intacta), 1 (fissuras), 0 (fibrilação, ruptura severa);

integridade da superfície: 2 (normal), 1 (ruptura leve, incluindo cistos), 0 (falta de integração severa);

espessura: 2 (100\% da cartilagem adjacente), 1 (51 - 99\% ou mais espessa que a normal), 0 (50\% da cartilagem normal);

integração com cartilagem adjacente: 2 (integridade total - ambas as bordas), 1 (parcial), 0 (ausente);

ausência de alterações degenerativas na cartilagem adjacente: 3 (celularidade normal, sem aglomerado, coloração normal), 2 (celularidade normal, aglomerados leves, coloração moderada);

condrócitos perilesionais: 3 (> 6 nas bordas), 2 (4 - 6 adjacente às bordas), 1 ( 1 - 3 adjacente às bordas);

morfologia celular na lesão: 3 (cartilagem hialina), 2 (principalmente hialina e fibrocartilagem), 1 (principalmente fibrocartilagem), 0 (somente células não condrocíticas);

coloração azul de toluidina da matriz na lesão: 2 (normal),1 (reduzida), 0 (sem coloração);

*colorações e imunomarcações: 3 (>75\%), 2 (26-75\%), 1 (6-25\%), 0 (nenhuma a 5\%).

Pontuação máxima total: 39 pontos. 
A análise morfométrica foi realizada utilizandose o analisador de imagens Leica Qwin, versão 3.1® (RGB), acoplado ao microscópio Leica ${ }^{\circledR}$ DM LB 80 com câmera digital DFC 290, sem conhecimento prévio dos grupos experimentais. A área do tecido de reparação foi mensurada, distinguindo-se o tecido fibroso e o fibrocartilaginoso.

Para análise imuno-histoquímica, após recuperação antigênica com solução de tampão citrato $(10 \mathrm{mM} \mathrm{pH} \mathrm{6,0)} \mathrm{em} \mathrm{micro-ondas,}$ bloqueio das peroxidades endógenas e inibição de interação inespecífica proteína-proteína, realizou-se a marcação da matriz extracelular utilizando-se os anticorpos anticolágeno tipo II (Policlonal Collagen type II (N-19) IgG, Lot \# G1505, Santa Cruz Biotechnology, CA, EUA) e antissulfato de condroitina (Monoclonal antichondroitin sulfate clone CS-56 (mouse), Sigma Aldrich Brasil Ltda.).

$\mathrm{Na}$ análise estatística das variáveis quantitativas estudadas, foi utilizada a técnica de análise de variância para o modelo com dois fatores, complementada com o teste de comparações múltiplas. Para as variáveis histopatológicas em escore, foi realizado o teste não paramétrico de Wilcoxon, enquanto para o total de pontos, o teste $\mathrm{t}$ de Student para amostras dependentes. A análise morfométrica foi realizada pelo teste não paramétrico de Wilcoxon, considerando-se 5\% de significância (Zar, 1999).

\section{RESULTADOS E DISCUSSÃO}

A coleta da cartilagem articular mostrou-se exequível e, por envolver as principais articulações, possibilitou o suprimento celular em quantidade necessária para implantação no defeito osteocondral. Isto pode ser explicado pelo fato de a espessura média da cartilagem ser de, aproximadamente, $0,7 \mathrm{~mm}$ comparada aos $3 \mathrm{~mm}$ da cartilagem humana (Brittberg et al., 1994). Destaca-se, no entanto, a morbidade de intervenção cirúrgica em várias articulações quando se utiliza o implante autólogo.

O processo de isolamento dos condrócitos da matriz extracelular foi adaptado de métodos descritos em outras espécies, os quais realizaram a pré-digestão com pronase (Park et al., 2006; Funayama et al., 2008), tripsina (Wakitani et al., 1998) e desoxirribonuclease (Frenkel et al.,
1997) para diminuir o tempo da colagenase. Contudo, apenas a colagenase foi utilizada para a digestão enzimática, promovendo o isolamento celular eficiente e, assim, reduzindo a complexidade da técnica sem causar efeitos deletérios. Essa metodologia está de acordo com outros autores que também eliminaram a prédigestão enzimática (Boopalan et al., 2006; Revell et al., 2008).

A contagem inicial do número de células dos cães de um e cinco anos totalizou, respectivamente, $1,5 \times 10^{5}$ e 0,7 × $10^{5}$ células/mL. A viabilidade dos condrócitos, no entanto, foi alta, $95 \%$, em ambos. A diferença de cultivo relacionada à idade do doador foi relatada tanto em humanos quanto no modelo animal, sendo a densidade celular e a taxa de proliferação inversamente proporcionais à idade do doador (Barbero et al., 2004). Esses dados corroboram os observados no presente trabalho quanto à variação do número inicial de células, do período para adesão celular ao frasco de cultura e da taxa de multiplicação dos condrócitos.

Apesar da diferença de concentração entre as duas culturas, os condrócitos foram cultivados em alta densidade ( 1 x $10^{5}$ células $\left./ \mathrm{mL}\right)$, comparável ao recomendado por Kitadai et al. (2003). A densidade celular apresenta efeito significativo na produção da matriz extracelular e subsequente resposta a estímulo mecânico (Revell et al., 2008). Neste estudo, a densidade recomendada foi estabelecida e houve evolução adequada da cultura.

O método de cultivo vertical adotado no estudo, além de simples e facilmente reproduzível, similar ao descrito por Park et al. (2006), apresenta como vantagem a estabilização do fenótipo dos condrócitos, dispensando a utilização de arcabouços. Assim, evitam-se a toxicidade dos produtos de degradação e as respostas imunes e/ou inflamatórias relacionadas a eles (Revell et al., 2008).

$\mathrm{Na}$ avaliação histológica, a ausência de sinais de osteoartrite demonstra que o procedimento cirúrgico para o implante de condrócitos homólogos não provocou alteração significativa nos joelhos dos animais operados, assim como relatado por Wakitani et al. (1998) em coelhos. 
Observou-se que o implante de condrócitos homólogos não proporcionou resposta imunológica pela análise histopatológica, evidenciada pela ausência de infiltrado celular significativo e pelas células gigantes. Outros experimentos com transplante de condrócitos alógenos em coelhos têm apresentado bons resultados quanto à reparação da cartilagem sem causar rejeição (Wakitani et al., 1998; Funayama et al., 2008). Apesar da forte expressão antigênica dessas células, o tecido cartilaginoso parece ser protegido de resposta imunológica tanto pela matriz extracelular, que apresenta pouca antigenicidade, quanto pelo fato de ser avascular (Boopalan et al., 2006). Adicionalmente, as células isoladas de cartilagem por meio de colagenase, como realizado neste estudo, não estão totalmente livres de matriz extracelular (Elves, 1974). Dessa forma, células cultivadas diminuem sua expressão antigênica e devem ter contribuído para essa resposta.

A ausência da membrana de celulose sobre os defeitos ressalta que esta sofreu degradação no organismo animal, assim como relatado por Iamaguti et al. (2008b). Além disso, Chen et al. (2009) estudaram a degradação da celulose e sua citotoxicidade in vitro para potencial utilização na engenharia tecidual do tecido ósseo, provando a característica biodegradável do biomaterial. Entretanto, neste trabalho, a membrana aplicada na base dos defeitos foi observada após 60 dias, indicando que a taxa de degradação desta, próxima do tecido ósseo, é bem mais lenta do que aquela em contato com o líquido sinovial. Dessa forma, a membrana justaposta ao tecido ósseo permaneceu praticamente inerte, atuando como uma barreira física.

Aos 60 dias do pós-operatório, todos os defeitos foram preenchidos por tecido fibroso ou fibrocartilaginoso, similar ao descrito com implante de condrócitos alógenos de coelhos (Funayama et al., 2008).

Neste estudo, utilizando condrócitos homólogos, a fase de avaliação foi mais precoce que os três meses descritos por Breinan et al. (1998) e Breinan et al. (2001) como o de melhor produção de células cartilaginosas. Entretanto, os resultados foram comparáveis aos obtidos nos períodos mais precoces e mais tardios. Diferentemente em coelhos, estudos mostraram a formação de tecido de reparação com presença de condrócitos viáveis e intensa coloração da matriz extracelular com seis semanas (Frenkel et al., 1997), um mês (Wakitani et al., 1998) e dois meses (Funayama et al., 2008) de avaliação, permanecendo até o período final, de seis meses, com características de tecido cartilaginoso. Dessa forma, deve-se ressaltar a diferença entre as espécies e o cuidado no extrapolamento direto de resultados entre elas.

O processo de reparação do GC foi caracterizado predominantemente por tecido fibroso organizado no centro e na periferia dos defeitos, com células fusiformes e núcleo alongado, intimamente associadas em torno da matriz de colágeno, orientados paralelamente à superfície sem lacunas (Fig. 1A). Entretanto, em cinco animais $(50 \%)$, o tecido de reparação da borda do defeito estava constituído por células arredondadas dentro de lacunas, o qual assumia aspecto de fibrocartilagem. Neste grupo foi notada presença de tecido de granulação e vasos sanguíneos na região do defeito. No GT, houve predomínio de tecido fibrocartilaginoso organizado na borda e no centro do defeito em todos os animais (100\%), com células arredondadas (Fig. 1B). A região analisada apresentava superfície lisa com presença de células cartilaginosas. Em duas secções (20\%), foi notada formação de tecido ósseo sobre a membrana de celulose. Neste grupo não foi observada evidência histológica de rejeição imunológica, como infiltrado de células mononucleares ao redor do implante.

A avaliação histológica de cada variável segundo a escala de pontuação está representada na Tab. 1.

A diminuição da intensidade da coloração do azul de toluidina em ambos os grupos experimentais pode ser explicada pela diminuição de proteoglicanos presentes no tecido de reparação, visto que a maioria das secções analisadas apresentava predomínio de tecido fibrocartilaginoso. No entanto, a ausência dessa coloração em mais secções do GC, quando comparado ao GT, enfatiza a prevalência do tecido fibroso deste grupo. Resultados semelhantes também foram observados na literatura consultada com implante de condrócitos alógenos em coelhos (Wakitani et 
al., 1998), apesar de o grupo-tratado apresentar melhor resposta do que o observado neste estudo.

A imunomarcação positiva com anticorpo anticolágeno II no GT indica que as células estão secretando quantidade limitada de colágeno tipo II na matriz extracelular. Contudo, essa pequena produção, cerca de $25 \%$, não diferencia o tecido neoformado em cartilagem hialina (Fig. 2A). De acordo com a literatura consultada, resultados favoráveis, com produção normal de colágeno tipo II evidenciada pela sua intensa imunomarcação, foram observados utilizando implante de condrócitos alógenos no sulco troclear de coelhos (Frenkel et al., 1997; Funayama et al., 2008). Esse fato, no entanto, pode ser explicado pela diferença de reparação da cartilagem articular entre as espécies animais, pois no cão não há descrição de resultados tão favoráveis. Já a marcação do sulfato de condroitina pode estar presente tanto na cartilagem hialina como no tecido fibroso e no fibrocartilaginoso (Roberts et al., 2003), e sua distribuição e intensidade variam quanto a idade e o estágio de desenvolvimento. Isso explica a ausência de diferença entre os grupos experimentais (Fig. 2B e C).
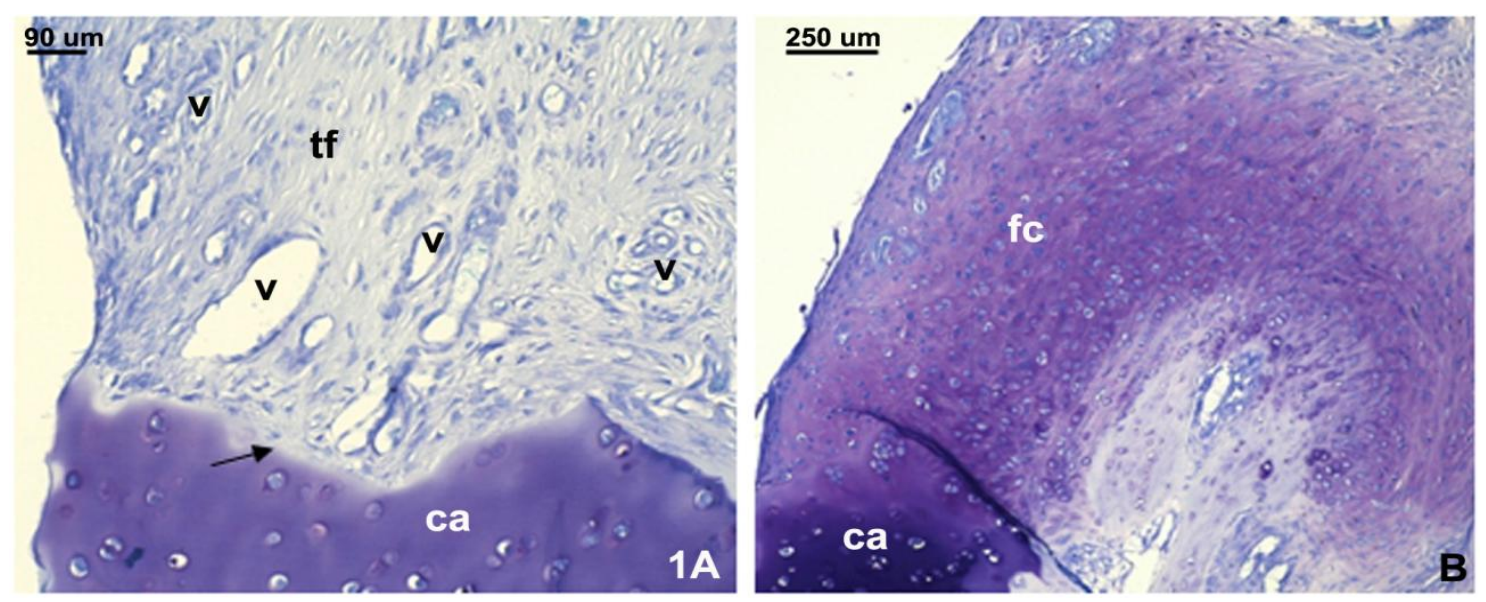

Figura 1. A) Fotomicrografia do defeito osteocondral do grupo de cães não tratados submetidos à artrotomia da articulação fêmoro-tíbio-patelar. Observar tecido fibroso (tf) organizado com muitos vasos (v) na periferia do defeito (seta). Células fusiformes com núcleo alongado em torno da matriz de colágeno tipo I orientadas paralelamente à superfície; B) fotomicrografia da região periférica do defeito osteocondral do grupo de cães tratados. Fibrocartilagem (fc) organizada e integrada com cartilagem adjacente (ca). (azul de toluidina).
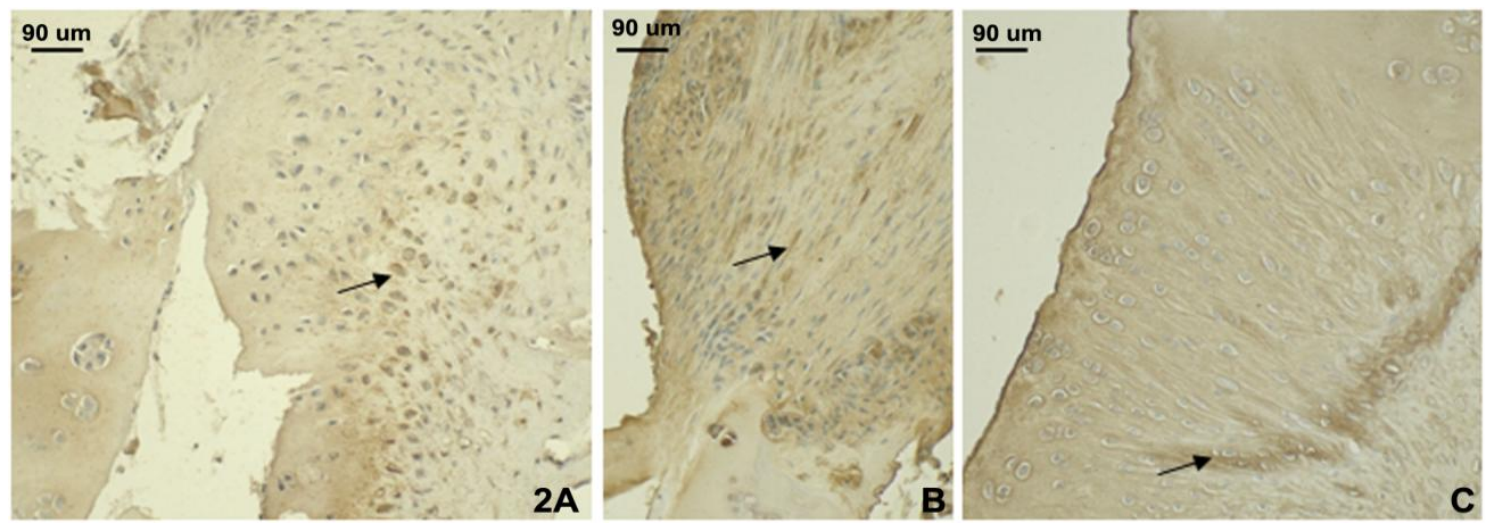

Figura 2. A) Fotomicrografia da imunomarcação com anticolágeno tipo II na periferia do defeito do grupo de cães tratados submetidos à artrotomia da articulação fêmoro-tíbio-patelar (seta); B) fotomicrografia da imunomarcação com antissulfato de condroitina do grupo de cães não tratados; e em C) do grupo de cães tratados. Notar evidência de sulfato de condrotinina na matriz extracelular (setas). 
Avaliação morfométrica da área do tecido de reparação com distinção entre o tecido fibroso e o fibrocartilaginoso está representada na Tab. 2. Dessa forma, apesar de o GT apresentar valores numéricos maiores de tecido fibrocartilaginoso e menores de fibroso comparado ao GC, esses dados não foram significativos. Resultados similares também foram relatados por Breinan et al. (2001), que avaliaram implante de condrócitos autólogos em cães. Os autores observaram que, aos 45 dias e após seis meses de avaliação, não houve diferença entre os grupos, prevalecendo a formação de tecido fibroso. Entretanto, aos três meses, houve diferença morfométrica entre os grupos experimentais, o que pode ser explicado, segundo o autor, pelo período de remodelamento tecidual.

Tabela 2. Mediana e valores mínimo e máximo em $\mu \mathrm{m}^{2}$ das áreas segundo os grupos em cães submetidos à artrotomia da articulação fêmoro-tíbio-patelar

\begin{tabular}{llll}
\hline Área & \multicolumn{1}{c}{ Controle } & \multicolumn{1}{c}{ Tratado } & Valor $\mathrm{p}$ \\
\hline Fibrocartilagem & $83804,2(5758,1 ; 158488,1)$ & $88809,5(4898,3 ; 259987,7)$ & $\mathrm{P}>0,05$ \\
Fibroso & $402618,2(223353,9 ; 1718583,5)$ & $367280,9(213642,0 ; 770708,2)$ & $\mathrm{P}>0,05$ \\
Total & $452966,9(287898,0 ; 1826250,7)$ & $456822,1(227703,7 ; 1030695,8)$ & $\mathrm{P}>0,05$ \\
\hline
\end{tabular}

O tecido de reparação com características ligeiramente superiores do GT sugere que o implante de condrócitos homólogos pode ter influenciado a liberação de fatores de crescimento provenientes do animal. Wakitani et al. (1998) relataram a atuação de fator de crescimento transformador $\beta$ ou proteínas ósseas morfogenéticas liberadas pelo indivíduo no processo de reparação da cartilagem. Talvez a ação sinérgica desta com a influência mecânica sobre o defeito tenham influenciado o resultado observado. A necessidade de mais experimentos, especialmente acrescentando outros fatores condrogênicos juntamente com o implante homólogo ou até mesmo autólogo, é, sem dúvida, indiscutível e essencial para confirmar a aplicação clínica dele.

Outra possibilidade que pode ter interferido na resposta encontrada pode ser a perda de células implantadas para o ambiente intra-articular. Como já citado, Breinan et al. (2001) relataram que a soltura do flape periosteal suturado sobre a região do defeito representa uma desvantagem da utilização de materiais que recobrem implantes de condrócitos.

Embora muitos métodos tenham sido desenvolvidos para o tratamento de defeitos da cartilagem articular, uma solução satisfatória de longa duração no cão ainda não foi encontrada e os tratamentos existentes parecem estar submetidos a problemas degenerativos (Breinan et al., 1998; Breinan et al., 2001; Sagliyan et al., 2009). O principal problema dos tratamentos é a deficiência de propriedades biomecânicas do novo tecido regenerado (Tins et al., 2005). Esses trabalhos, associados aos observados no presente estudo, têm falhado em obter regeneração de defeitos de cartilagem em cães.

\section{CONCLUSÕES}

A técnica de cultura de condrócitos de cães é exequível e promove proliferação celular no cultivo inicial em monocamada. $\mathrm{O}$ cultivo vertical é adequando para a manutenção dos fenótipos dos condrócitos e favorece a implantação. O tecido de reparação apresenta qualidade discretamente superior quando associado ao implante homólogo de condrócitos, considerando-se predomínio de células com características condrocíticas e de colágeno tipo II. Contudo, não promove reparação por cartilagem hialina. A membrana de biossintética de celulose apresenta boa adaptação e integração tecidual em ambiente intra-articular.

\section{AGRADECIMENTOS}

Ao CNPq, pela bolsa, e à Fundunesp, pelo auxílio à pesquisa; ao Laboratório Ouro Fino, pela doação do Maxicam ${ }^{\circledR}$, e à Vetbrands, pela doação do Enropet ${ }^{\circledR}$. 


\section{REFERÊNCIAS}

ASLAN, M.; SIMSEK, G.; DAYL, E. Guided bone regeneration (GBR) on healing bone defects: a histological study in rabbits. $J$. Contemp. Dent. Pract., v.2, p.114-123, 2004.

BARBERO, A.; GROGAN, S.; SCHÄFER, D. et al. Age related changes in human articular chondrocyte yield, proliferation and postexpansion chondrogenic capacity. Osteoart. Cart., v.12, p.476-484, 2004.

BOOPALAN, P.R.J.V.C.; SATHISHKUMAR, S.; KUMAR, S. et al. Rabbit articular cartilage defects treated by allogenic chondrocyte transplantation. Int. Orthop., v.30, p.357-361, 2006.

BREINAN, H.A.; MINAS, T.; BARONE, L. et al. Histological evaluation of the course of healing canine articular cartilage defects treated with cultured autologous chondrocytes. Tissue Eng., v.4, p.101-113, 1998.

BREINAN, H.A.; MINAS, T.; HSU, H.P. et al. Autologous chondrocyte implantation in a canine model: change in composition of reparative tissue with time. J. Orthop. Res., v.19, p.482492, 2001.

BRITTBERG, M.; LINDAHL, A.; NILSSON, A. et al. Treatment of deep cartilage defects in the knee with autologous chondrocytes transplantation. N. Engl. J. Med., v.331, p.889985, 1994

CHEN, Y.M.; XI, T.; ZHENG, Y. et al. In vitro cytotoxicity of bacterial cellulose scaffolds used for tissue-engineered bone. J. Bioact. Comp. Polymers., v.24, p.137- 145, 2009.

ELVES, M.W. A study of the transplantation antigens on chondrocytes from articular cartilage. J. Bone Jt. Surg., v.56B, p.178-185, 1974.

FRENKEL, S.R.; TOOLAN, B.; MENCHEN, D. et al. Chondrocyte transplantation using a collagen bilayer matrix for cartilage repair. $J$. Bone Jt. Surg., v.79-B, p.831-836, 1997.

FUNAYAMA, A.; NIKI, Y.; MATSUMOTO, H. et al. Repair of full-thickness articular cartilage defects using injectable type II collagen ggel embedded with cultured chondrocytes in a rabbit model. J. Orthop. Sci., v.13, p.225-232, 2008.
IAMAGUTI, L.S.; BRANDÃO, C.V.S.; MINTO, B.W. et al. Utilização de membrana biossintética de celulose na trocleoplastia experimental em cães. Avaliações clínica, radiográfica e macroscópica. Vet. Zootec., v.15, p.160-168, 2008a.

IAMAGUTI, L.S.; BRANDÃO, C.V.S.; PELLIZZON, C.H. et al. Análise histológica e morfométrica do uso de membrana biossintética de celulose em trocleoplastia experimental de cães. Pesq. Vet. Bras., v.28, p.195-200, 2008 b.

KITADAI, F.; FIGUEIREDO, C.A.; CURTI, S.P. et al. Cultura primária de condrócitos articular humana em monocamada. Rev. Inst. Adolfo Lutz., v.62, p.221-226, 2003.

O' DRISCOLL, S.W.; KEELEY, F.W.; SALTER, R.B. The chondrogenic potential of free autogenous periosteal grafts for biological resurfacing of major full-thickness defects in joint surfaces under the influence of continuous passive motion, an experimental investigation in the rabbit. J. Bone \& Jt. Surg., v.68, p.10171035, 1986.

PARK, K.; HUANG, J.; AZAR, F. et al. Scaffold-free, engineered porcine cartilage construct for cartilage defect repair - in vitro and vivo study. Artif. Org., v.30, p.586-596, 2006.

PINEDA, S.; POLLACK, A.; STEVENSON, S. et al. A semiquantitative scale for histologic grading of articular cartilage repair. Acta Anat. Basel., v.143, p.335-340, 1992.

REVELL, C.M.; REYNOLDS, C.E.; ATHANASIOU, K.A. Effects of initial cell seeding in assembly of articular cartilage. Annals Biomed. Engin., v.36, p.1441-1448, 2008.

ROBERTS, S.; McCALL, I.W.; DARBY, A.J. et al. Autologous chondrocyte implantation for cartilage repair: monitoring its success by magnetic resonance imaging and histology. Arthritics Res. Ther., v.5, p.R60-R73, 2003.

SAGLIYAN, A.; KARABULUT, E.; UNSALDI, E. et al. Evaluation of the activity of intraarticular hyaluronic acid in the repair of experimentally induced osteochondral defects of the stifle joint in dogs. Vet. Med., v.54, p.33-40, 2009. 
TINS, B.J.; MCCALL, I.W.; TAKAHASHI, T. et al. Autologous chondrocyte implantation in knee joint: MR imaging and histologic features at 1-year follow-up. Radiology, v.234, p.501508, 2005.

VAN DER KRAAN, P.M.; BUMA, P.; VAN KUPPEVET, $\mathrm{T}$. et al. Interaction of chondrocytes, extracellular matrix and growth factors: relevance for articular cartilage tissue engineering. Osteoart. Cart., v.10, p.631-637, 2002.
WAKITANI, S.; GOTO, R.; YOUNG, R.G. et al. Repair of large full-thickness articular cartilage defects with allograft articular chondrocytes embedded in a collagen gel. Tissue Eng., v.4, p.429-444, 1998.

WILKE, M.M.; NYDAM, D.V.; NIXON, A.J. Enhanced early chondrogenesis in articular defects following arthroscopic mesenchymal stem cell implantation in an equine model. $J$. Orthop. Res., v.25. p.913-925, 2007.

ZAR, J.H. Biostatistical analysis. 4th ed. New Jersey: Prentice Hal, 1999. 663p. 